\begin{tabular}{|c|c|c|c|c|}
\hline JURNAL & VOLUME 1 & NOMOR 1 & HALAMAN 1-70 & $\begin{array}{r}\text { ISSN 2655-8823 }(p) \\
\text { ISSN - }(e)\end{array}$ \\
\hline
\end{tabular}

\title{
KONFLIK AGRARIA ANTARA ALIANSI GERAKAN REFORMA AGRARIA (AGRA) PANGALENGAN DENGAN PERUSAHAAN DAERAH AGRIBISNIS DAN PERTAMBANGAN (PDAP)
}

\author{
Dinda Primayanti \\ Mahasiswa Program Studi Kesejahteraan Sosial FISIP UNPAD \\ E-mail:dprimayanti22@gmail.com \\ Muhammad Fedryansyah \\ Dosen Program Studi Kesejahteraan Sosial FISIP UNPAD \\ E-mail: m.fedryansyah@unpad.ac.id
}

\begin{abstract}
ABSTRAK
Konflik agraria adalah salah satu bentuk konflik yang sering terjadi di Indonesia. Provinsi Jawa Barat merupakan salah satu wilayah yang rentan terjadi konflik agraria. Penelitian ini bertujuan untuk mengetahui kronologis terjadinya konflik, tipe konflik, dan penyebab dari konflik agraria antara Aliansi Gerakan Reforma Agraria (AGRA) Pangalengan dengan Perusahaan Daerah Agribisnis dan Pertambangan (PDAP). Penelitian ini menggunakan metode studi literatur. Jenis penelitian studi literatur adalah mencari referensi teori yang relevan dengan kasus atau permasalahan yang ditemukan. Berdasarkan hasil analisis yang dilakukan, diketahui bahwa konflik agraria antara Aliansi Gerakan Reforma Agraria (AGRA) Pangalengan dengan Perusahaan Daerah Agribisnis dan Pertambangan (PDAP) termasuk ke dalam tipe konflik terbuka. Selain itu, penyebab konflik yang terjadi tersebut juga dianalisis dengan menggunakan teori hubungan masyarakat dan teori negosiasi prinsip.
\end{abstract}

Kata Kunci : konflik agraria, analisis konflik, tipe konflik

\section{ABSTRACT}

Agrarian conflict is one form of conflict that often occurs in Indonesia. West Java Province is one of the areas prone to agrarian conflicts. This study aims to determine the chronology of the occurrence of conflict, the type of conflict and the causes of agrarian conflicts between the Aliansi Gerakan Reforma Agraria (AGRA) Pangalengan and Perusahaan Daerah Agribisnis dan Pertambangan (PDAP). This study uses the literature study method. This type of literature study research is looking for theoretical references that are relevant to cases or problems found. Based on the results of the analysis of agrarian conflicts between the Aliansi Gerakan Reforma Agraria (AGRA) Pangalengan and Perusahaan Daerah Agribisnis dan Pertambangan (PDAP) belong to the type of open conflict and the causes of conflict are analyzed using public relations theory and principle negotiation theory.

Keywords: agrarian conflict, conflict analysis, type of conflict

\section{PENDAHULUAN}

Menurut Soerjono Soekanto (2006: 91) konflik merupakan perbedaan atau pertentangan antar individu atau kelompok sosial yang terjadi karena perbedaan kepentingan, serta adanya usaha memenuhi tujuan dengan jalan menentang pihak lawan disertai dengan ancaman atau kekerasan. Salah satu bentuk konflik yang sering terjadi di Indonesia adalah konflik agraria. Menurut Konsorsium Performa Agraria (KPA) terdapat lima provinsi penyumbang konflik agraria terbesar, yaitu Jawa Timur (60 konflik), Sumatera Utara (59 konflik), Jawa Barat (55 konflik), Riau (47 konflik), dan Lampung (35 konflik). Kelima provinsi tersebut menyumbang 38,85 persen dari total 659 konflik agraria yang terjadi di Indonesia selama tahun 2017 (Sumber: www.tirto.id).

Provinsi Jawa Barat merupakan salah satu wilayah yang rentan terjadi konflik agraria. Salah satu contoh kasus konflik 


\begin{tabular}{|c|c|c|c|c|}
\hline $\begin{array}{c}\text { JURNAL } \\
\text { KOLABORASI RESOLUSI KONFLIK }\end{array}$ & VOLUME 1 & NOMOR 1 & HALAMAN 1-70 & $\begin{array}{r}\text { ISSN 2655-8823 }(p) \\
\text { ISSN - }(e)\end{array}$ \\
\hline
\end{tabular}

agraria yang terjadi di Jawa Barat adalah konflik lahan antara AGRA Pangalengan dengan PDAP. Konflik tersebut telah terjadi sejak tahun 2003. Konflik ini bermula ketika tanah di Pangalengan tersebut adalah lahan perusahaan daerah milik Pemprov Jabar bernama PD Mamin. Karena keterbatasan modal, PD Mamin tidak mengelola lahan tersebut dan menelantarkannya. Penelantaran lahan tersebut dimanfaatkan oleh petani untuk menggarap lahannya sejak tahun 2000. Pada tahun 2003 PDAP datang mengklaim bahwa tanah seluas 134 hektar tersebut adalah haknya. PDAP merupakan perusahaan hasil akuisisi dari PD Mamin dan tiga perusahaan daerah. Secara legalitas memang lahan tersebut merupakan hak PDAP. Akan tetapi petani penggarap atau AGRA Pangalengan mengklaim bahwa terdapat UU Pokok Agraria yang menjelaskan bahwa tanah tidak boleh diterlantarkan. Satu ketentuan di dalam UU Pokok Agraria menyebutkan, hak atas tanah hilang karena ditelantarkan dan tidak diurus. Sehingga menurut AGRA Pangalengan tanah tersebut bukan lagi hak milik PDAP. Konflik lahan antara AGRA Pangalengan dengan PDAP terus berlarut-larut karena belum adanya kesepakatan antara kedua belah pihak.

Berdasarkan isu konflik tersebut dalam penanganan konfliknya perlu diketahui terlebih dahulu kronologis terjadinya konflik, tipe konflik dan penyebab dari konflik tersebut. Oleh karena itu, penelitian ini dilakukan untuk membahas konflik agraria antara AGRA Pangalengan dengan PDAP.

\section{TINJAUAN PUSTAKA}

Konflik berasal dari Bahasa Latin "configure" yang berarti saling memukul. Secara sosiologis, konflik merupakan suatu proses antara dua orang atau lebih yang salah satu pihak berusaha menyingkirkan pihak lain dengan menghancurkannya atau membuatnya tidak berdaya. Sedangkan menurut Pruitt dan Rubin (2004) konflik adalah persepsi mengenai perbedaan kepentingan atau suatu kepercayaan bahwa aspirasi pihak-pihak yang berkonflik tidak dapat dicapai secara simultan.

Menurut Fisher, dkk. (2000: 5) mengungkapkan bahwa konflik dibedakan menjadi dua sumbu: sasaran dan perilaku. Sesuai dengan definisi, bahwa konflik merupakan hubungan antara dua pihak atau lebih (individu atau kelompok) yang memiliki atau merasa memiliki, sasaransasaran yang tidak sejalan. Terdapat empat tipe konflik yang memiliki potensi dan tantangannya sendiri, yaitu sebagai berikut:

1. Tanpa konflik, setiap kelompok atau masyarakat yang hidup dengan damai dan ingin keadaan tersebut terus berlangsung, maka harus hidup bersemangat dan dinamis dengan memanfaatkan konflik perilaku dan tujuan serta mengelola konflik secara kreatif.

2. Konflik laten, sifatnya tersembunyi sehingga perlu diangkat ke permukaan agar dapat ditangani secara efektif.

3. Konflik terbuka, yaitu konflik yang berakar dalam dan sangat nyata. Konflik ini memerlukan berbagai tindakan untuk mengatasi akar penyebab dan berbagai efeknya.

4. Konflik di permukaan, konflik yang memiliki akar dangkal atau bahkan tidak berakar. Konflik ini muncul hanya karena kesalahpahaman mengenai sasaran yang dapat diatasi dengan meningkatkan komunikasi.

Dalam memahami cara-cara mengelola konflik terdapat beberapa teori mengenai berbagai penyebab konflik. Untuk mengetahui penyebab konflik agraria antara AGRA Pangalengan dengan PDAP, digunakan dua teori, yaitu teori hubungan masyarakat dan teori negosiasi prinsip. Teori hubungan masyarakat menganggap bahwa 
konflik disebabkan oleh polarisasi yang terus terjadi, ketidakpercayaan dan permusuhan di antara kelompok yang berbeda dalam suatu masyarakat. Teori ini mengemukakan komunikasi yang jarang terjalin dan tidak saling pengertian antar dua kelompok masyarakat yang menjadi potensi konflik, serta tidak ada toleransi dalam lingkungan tersebut. Sasaran yang ingin dicapai dalam teori ini adalah meningkatkan komunikasi dan saling pengertian antara kelompokkelompok yang mengalami konflik. Selain itu, untuk mengusahakan toleransi dan agar masyarakat lebih saling menerima keragaman yang ada di dalamnya.

Sedangkan teori negosiasi prinsip beranggapan bahwa konflik disebabkan oleh posisi-posisi yang tidak selaras dan terdapat perbedaan pandangan tentang konflik oleh pihak-pihak yang sedang mengalami konflik. Dalam teori ini sasaran yang ingin dicapainya adalah membantu pihak-pihak yang mengalami konflik untuk memisahkan perasaan pribadi dengan berbagai masalah dan isu, dan memampukan mereka untuk melakukan negosiasi berdasarkan atas kepentingan-kepentingan mereka daripada posisi tertentu yang sudah tetap. Selain itu, yang ingin dicapai dalam teori ini adalah untuk melancarkan proses pencapaian kesepakatan yang menguntungkan kedua belah pihak atau semua pihak. Pada suatu konflik diusahakan agar bias memisahkan perasaan pribadi dengan masalah yang terjadi, sehingga dapat dilakukan negosiasi berdasarkan kepentingan-kepentingan dan ketetapan yang sudah ada dan diharapkan mampu dicapainya kesepakatan yang menguntungkan kedua belah pihak (Fisher, 2000: 8).

\section{METODE PENELITIAN}

Penelitian ini termasuk ke dalam jenis penelitian studi literatur. Jenis penelitian studi literatur adalah mencari referensi teori yang relevan dengan kasus atau permasalahan yang ditemukan. Dalam melakukan penelitian ilmiah ini, digunakan teknik penyusunan secara sistematis untuk memudahkan langkah-langkah yang akan diambil. Kajian literatur diarahkan pada buku-buku yang membahas konflik, jurnal, berita dan penelitian yang telah dilakukan berkaitan dengan konflik agraria antara AGRA Pangalengan dengan PDAP.

\section{HASIL DAN PEMBAHASAN}

Konflik antara petani penggarap dengan PDAP telah terjadi sejak 2003. Proses penyelesaian konflik tersebut masih berlarut larut. Belum ditemukan titik kesepakatan antara AGRA Pangalengan dengan PDAP. Hingga berujung upaya kriminalisasi terhadap beberapa petani penggarap. Awalnya tanah garapan petani di Pangalengan adalah lahan perusahaan daerah milik Pemprov Jabar bernama PD Mamin. Perusahaan itu menguasai lahan karena mempunyai hak pengelolaan lahan. Akan tetapi, selama bertahun-tahun PD Mamin menelantarkan lahan itu karena ketidak mampuan daya dukung finansial. Oleh karena itu, lahan tersebut dimanfaatkan oleh petani dan mulai digarap sejak tahun 2000 .

Mulai tahun 2003 PDAP mengklaim tanah seluas 134 hektar itu hak mereka. Perusahaan ini didirikan 23 September 1998, hasil akuisisi dari PD Mamin dan tiga perusahaan daerah. Akan tetapi pihak AGRA mengklaim bahwa terdapat UU Pokok Agraria yang menjelaskan bahwa tanah tidak boleh diterlantarkan. Satu ketentuan di dalam UU Pokok Agraria menyebutkan, hak atas tanah hilang karena ditelantarkan dan tidak diurus. Sehingga menurut AGRA tanah tersebut bukan lagi hak milik PDAP. PDAP mengajak petani untuk bermitra agar tidak ada pihak yang dirugikan. Program kemitraan dengan para petani ditawarkan sesuai surat rekomendasi Ketua DPRD Bandung pada 2005. Isi surat rekomendasi itu menganjurkan konflik di Pangalengan 
diselesaikan secara kekeluargaan agar tidak ada pihak yang dirugikan. Point tawaran kerjasama antara PDAP dan petani penggarap itu antara lain, PDAP menyediakan bibit dan pupuk tanaman holtikultura, petani penggarap boleh menggarap lahan. Nanti, ada pembagian hasil yang disebut dengan istilah maro, atau 50:50. Pada awalnya beberapa warga menyepakati program kerja sama tersebut. Namun setelah diketahui bahwa lahan yang menjadi sasaran program tersebut adalah lahan Sampalan, maka warga menolak kesepakatan tersebut dan meminta agenda pembahasan tersebut diulang kemudian hari dan bersama angota AGRA. Setelah dilakukan beberapa kali upaya sosialisasi program kemitraan dengan para petani penggarap hasilnya tidak pernah menemukan titik temu. Pihak AGRA dan PDAP masih sama-sama ingin mengklaim lahan tersebut.

Konflik agraria antara AGRA Pangalengan dengan PDAP terus berlarutlarut. Sebelumnya, beberapa konflik antara para petani dengan PDAP pernah terjadi. Tahun 2006, perusahaan bersama preman berusaha membuldozer lahan garapan petani dengan dalih dipakai. Karena ada tanaman warga maka warga bertahan dan berusaha untuk melawan. Terdapat konflik fisik tetapi tidak sampai menimbulkan korban jiwa, masyarakat hanya memblokir alat berat tersebut. Penyelesaian kasus tersebut difasilitasi oleh DPRD tetapi pertemuan dengan DPRRD tidak menyelesaikan konflik. Pada saat itu masing-masing pihak hanya diminta menahan diri tanpa ada solusi yang jelas.

Konflik semakin memuncak ketika PDAP melaporkan beberapa masyarakat kepada pihak kepolisian. Pihak AGRA Pangalengan beranggapan bahwa PDAP melakukan tindakan kriminalisasi dalam bentuk pengaduan pada pihak Polres Bandung dengan tuntutan KUHP pasal 385 tentang penggelapan tanah di atas lahan bersertifikat serta Perpu NO 51 pasal 06 tahun 1960 tentang kondisi darurat. Konflik sengketa lahan yang terjadi antara AGRA Pangalengan dengan PDAP melalui bentuk kekerasan pada tahun 2004, penyuapan pada tahun 2005 dan pada tahun 2011 dengan bentuk upaya kemitraan akan tetapi menimbulkan kriminalisasi.

Pada Juni 2011 AGRA Pangalengan menggelar aksi massa ke Gedung Sate dengan jumlah massa sekitar 700 orang dengan arahan beraudiensi bersama dewan komisi A dan $\mathrm{C}$ dengan tuntutan: cabut gugatan hukum PDAP, Bubarkan Tim 30 bentukan PDAP, hentikan segala bentuk intimidasi terhadap petani penggarap Sampalan, serta dikemudian hari minta dipertemukan dengan pihak BPN untuk membahas soal ajuan legalisasi seperti yang telah dilakukan AGRA Pangalengan pada tahun 2006. Pihak dewan komisi A dan C akan merespon dengan menghentikan tindakan kriminalisasi dari PDAP serta mengadakan forum bersama antara AGRA Pangalengan, PDAP, Perangkat Desa Marga Mekar, dan BPN untuk membahas status lahan sampalan dikemudian hari. Dengan syarat penyusunan sejarah lahan dan menghadirkan ahli sejarahnya, dan surat $\mathrm{C}$ dari Desa. Akan tetapi, penyelesaian konflik masih belum jelas. Beberapa anggota AGRA malah kembali mendapatkan surat panggilan dari pihak kepolisian atas laporan pihak PDAP. Masyarakat yang dilaporkan pihak PDAP divonis delapan bulan penjara pada April 2013 dan resmi ditahan. Pelaporan dan penahanan beberapa masyarakat tersebut diakui pihak PDAP untuk membuka kesadaran petani yang lain bahwa menduduki lahan hak orang lain adalah salah di mata hukum. Di vonisnya beberapa anggota AGRA Pangalengan tidak menjadi akhir konflik antara kedua pihak tersebut. Setelah vonis keluar, serangkaian peristiwa terjadi dan berujung pada bentrokan di depan kantor PDAP. Pihak AGRA Pangalengan 


\begin{tabular}{|c|c|c|c|c|}
\hline $\begin{array}{c}\text { JURNAL } \\
\text { KOLABORASI RESOLUSI KONFLIK }\end{array}$ & VOLUME 1 & NOMOR 1 & HALAMAN 1-70 & $\begin{array}{r}\text { ISSN 2655-8823 }(p) \\
\text { ISSN - }(e)\end{array}$ \\
\hline
\end{tabular}

mengungkapkan bahwa PDAP telah mengkriminalisasi anggota AGRA Pangalengan. Konflik antara petani penggarap dengan PDAP itu sudah terjadi sejak tahun 2003. Proses penyelesaian berlarut larut. PDAP dan petani penggarap tidak pernah menemukan titik kesepakatan.

Untuk memahami konflik yang terjadi tersebut dapat dimulai dari identifikasi tipe konflik. Konflik memiliki beberapa tipe, tipe konflik tersebut masing-masing memiliki potensi dan tantangannya sendiri. Jika dianalisis konflik agraria antara AGRA Pangalengan dengan PDAP termasuk ke dalam tipe konflik terbuka. Sebab konflik agraria antara AGRA Pangalengan dengan PDAP berakar dalam dan sangat nyata, dan memerlukan berbagai tindakan untuk mengatasi akar penyebab dan berbagai efeknya. Konflik ini telah terlihat bahwa perebutan lahan yang terjadi sebenarnya sudah jelas pemilik lahannya. Akan tetapi, kedua belah pihak masih bersikeras dan masyrakat masih tidak mau memberikan lahan garapannya kepada perusahaan, sehingga konflik masih terus berlangsung dan berlarut-larut.

Dalam memahami cara-cara mengelola konflik dapat dibantu dengan menganalisis konflik menggunakan teori-teori mengenai berbagai penyebab konflik. Konflik agraria antara AGRA Pangalengan dengan PDAP selaras dengan teori hubungan masyarakat. Dalam teori hubungan masyarakat konflik disebabkan karena polarisasi yang terus terjadi, ketidakpercayaan dan permusuhan diantara kelompok yang berbeda dalam suatu masyarakat. Dalam konflik ini para petani atau masyarakat memiliki rasa ketidakpercayaan terhadap PDAP dan kedua belah pihak saling bersikeras, sehingga sulit untuk menemukan kesepakatan yang menguntungkan kedua belah pihak. Ketidakpercayaan para petani atau AGRA Pangalengan terhadap PDAP membuat perusahaan melakukan berbagai tekanan yang berujung kriminalisasi pada petani. Oleh sebab itu, dalam teori hubungan masyarakat sasaran yang ingin dicapai dalam teori ini adalah meningkatkan komunikasi dan saling pengertian antara masyarakat dengan perusahaan. Selain itu, sasaran yang ingin dicapai lainnya adalah mengusahakan toleransi dan agar masyarakat lebih bisa saling menerima keragaman yang ada di dalamnya.

Teori lainnya yang dapat menjadi alat bantu untuk mengetahui mengenai penyebab konflik lahan antara AGRA Pangalengan dengan PDAP adalah teori negosiasi prinsip. Dalam teori ini, konflik disebabkan oleh posisi-posisi yang tidak selaras dan perbedaan pandangan tentang konflik oleh pihak-pihak yang mengalami konflik. Dalam hal ini konflik terjadi sebab perbedaan pandangan antara masyarakat dengan perusahaan. Kedua belah pihak sama-sama bersikeras ingin mengklaim lahan tersebut walaupun sudah jelas diketahui pemilik lahannya. Kedua belah pihak saling memiliki argumen atas hak kepemilikan lahan tersebut. Sekian lama konflik berlangsung belum adanya kesepakatan yang menguntungkan kedua belah pihak. Dengan begitu sasaran yang ingin dicapai oleh teori ini adalah membantu pihak-pihak yang mengalami konflik untuk memisahkan perasaan pribadi dengan berbagai masalah, isu, dan memampukan mereka untuk melakukan negosiasi berdasarkan kepentingankepentingan mereka daripada proses tertentu yang sudah tetap. Selain itu, sasaran lainnya adalah untuk melancarkan proses pencapaian kesepakatan yang menguntungkan kedua belah pihak antara masyarakat dengan perusahaan.

\section{KESIMPULAN DAN SARAN}

Konflik yang terjadi antara kelompok masyarakat dengan perusahaan di Pangalengan dapat disebut sebagai konflik agraria. Konflik tersebut telah terjadi sejak 


\begin{tabular}{|c|c|c|c|c|}
\hline $\begin{array}{c}\text { JURNAL } \\
\text { KOLABORASI RESOLUSI KONFLIK }\end{array}$ & VOLUME 1 & NOMOR 1 & HALAMAN 1-70 & $\begin{array}{c}\text { ISSN 2655-8823 }(p) \\
\text { ISSN - }(e)\end{array}$ \\
\hline
\end{tabular}

tahun 2003 dan dimulai dari adanya penelantaran lahan oleh perusahaan. Penelantaran lahan tersebut kemudian dimanfaatkan oleh petani untuk bercocok tanam. Pada tahun 2003 PDAP datang mengklaim bahwa tanah seluas 134 hektar tersebut adalah haknya. Akan tetapi atau AGRA Pangalengan mengklaim bahwa terdapat UU Pokok Agraria yang menjelaskan bahwa tanah tidak boleh diterlantarkan. Satu ketentuan di dalam UU Pokok Agraria menyebutkan, hak atas tanah hilang karena ditelantarkan dan tidak diurus. Sehingga menurut AGRA Pangalengan tanah tersebut bukan lagi hak milik PDAP. Konflik agraria antara AGRA Pangalengan dengan PDAP terus berlarut-larut karena belum adanya kesepakatan antara kedua belah pihak.

Konflik agraria antara AGRA Pangalengan dengan PDAP termasuk ke dalam tipe konflik terbuka. Sebab konflik agraria antara AGRA Pangalengan dengan PDAP berakar dalam dan sangat nyata, dan memerlukan berbagai tindakan untuk mengatasi akar penyebab dan berbagai efeknya. Terdapat dua teori yang dapat digunakan untuk mengetahui penyebab konfliknya, yaitu teori hubungan masyarakat dan teori negosiasi prinsip. Berdasarkan analisis teori hubungan masyarakat, para petani atau masyarakat memiliki rasa ketidakpercayaan terhadap PDAP dan kedua belah pihak saling bersikeras, sehingga sulit untuk menemukan kesepakatan yang menguntungkan kedua belah pihak. Sedangkan teori negosiasi prinsip konflik terjadi sebab perbedaan pandangan antara masyarakat dengan perusahaan. Kedua belah pihak sama-sama bersikeras ingin mengklaim lahan tersebut walaupun sudah jelas diketahui pemilik lahannya. Kedua belah pihak saling memiliki argumen atas hak kepemilikan lahan tersebut.

Saran untuk penyelesaian konflik adalah perlu adanya komunikasi yang baik dan efektif antara kedua belah pihak yaitu AGRA Pangalengan dengan PDAP yang difasilitasi oleh pemerintah. Pemerintah perlu untuk terlibat dalam penyelesaian konflik yang terjadi antara kedua belah pihak tersebut. Pemerintah harus mampu mengelola konflik secara konstruktif sehingga sumber-sumber penyebab konflik dapat ditangani tanpa melalui kekerasan. Pemerintah yang baik yaitu yang memiliki kombinasi antara berbagai lembaga, hukum, peraturan serta norma yang memberikan kesempatan kepada masyarakatnya untuk berpartisipasi dan menyuarakan pendapatnya melalui cara-cara yang adil. Meningkatkan komunikasi antara kedua pihak yang sedang berkonflik adalah salah satu hal yang penting untuk dilakukan dalam penyelesaian konflik tersebut.

\section{DAFTAR PUSTAKA}

Fisher, Simon dkk. 2000. Mengelola Konflik: Keterampilan dan Strategi untuk Bertindak. Terjemahan oleh S.N Kartikasari dkk. Indonesia: The British Council.

Pruitt, D.G. dan J.Z. Rubin. 2004. Teori

Konflik Sosial. Yogyakarta: Pustaka Pelajar.

Soekanto, Soerjono. 2006. Sosiologi Suatu Pengantar. Jakarta: Raja Grafindo Persada.

Sulistyati, Tri dkk. 2014. Analisis Konflik Lahan Eks Kpwn Di Desa Teja, Kecamatan Rajagaluh, Kabupaten Majalengka, Provinsi Jawa Barat. Jurnal Penelitian Agroforestry Vol. 2 No. 2, Desember 2014 (hal. 57-66).

Apinino, Rio. 2017. Dua Konflik Per Hari, Catatan Buram Konflik Agraria di 2017. https:/tirto.id/dua-konflik-per-haricatatan-buram-konflik-agraria-di-2017cCmU.

Nugraha, Indra. 2013. Konflik Lahan Petani dan PDAP di Pengalengan Berlarut. http://www.mongabay.co.id/2013/06/04/ 


\begin{tabular}{|c|c|c|c|c|}
\hline $\begin{array}{c}\text { JURNAL } \\
\text { KOLABORASI RESOLUSI KONFLIK }\end{array}$ & VOLUME 1 & NOMOR 1 & HALAMAN 1-70 & $\begin{array}{r}\text { ISSN 2655-8823 }(p) \\
\text { ISSN - }(e)\end{array}$ \\
\hline
\end{tabular}

konflik-lahan-petani-dan-pdap-di-

pengalengan-berlarut/

Nugraha, Indra. 2013. Buntut Konflik dengan

PDAP, Dua Petani Pengalengan Divonis

8

Bulan.

http://www.mongabay.co.id/2013/04/06/

buntut-konflik-dengan-pdap-dua-petani-

pengalengan-divonis-8-bulan/

Bandung Melawan. 2015. Kronologis

Konflik Lahan Antara AGRA AC

Pangalengan dengan

PDAP.https://www.kompasiana.com/ban

dungmelawan/55088533a3331135322e3

97e/kronologis-konflik-lahan-antara-

agra-ac-pangalengan-dengan-pdap

Ratusan Petani AGRA Jabar-Banten Minta

PDAP Hentikan Aksi Kriminalisasi.

http://www.pikiran-

rakyat.com/bandungraya/2011/07/29/15

3577/ratusan-petani-agra-jabar-banten-

minta-pdap-hentikan-aksi 